\title{
Does the euro dominate Central and Eastern European money markets? *
}

\author{
Mario Cerrato \\ University of Glasgow
}

\author{
Alexander Kadow ${ }^{\dagger}$ \\ University of Glasgow \\ Stefan Straetmans \\ Maastricht University
}

July 30, 2010

\author{
Ronald MacDonald \\ University of Glasgow
}

\begin{abstract}
The so-called German Dominance Hypothesis (GDH) claimed that Bundesbank policies were transmitted into other European Monetary System (EMS) interest rates during the pre-euro era. We reformulate this hypothesis for the Central and Eastern European (CEE) countries that are on the verge of accessing the eurozone. We test this "Euro Dominance Hypothesis (EDH)" in a novel way using a global vector autoregressive (GVAR) approach that combines country-specific error correction models in a global system. We find that euro area monetary policies are transmitted into CEE interest rates which provides evidence for monetary integration between the eurozone and CEE countries. Our framework also allows for introducing global monetary shocks to provide empirical evidence regarding the effects of the recent financial crisis on monetary integration in Europe.
\end{abstract}

JEL classification: E58, F36, G15.

Keywords: German Dominance Hypothesis, Global VAR, Central and Eastern Europe, monetary integration, European integration.

${ }^{*}$ We are grateful to David Cobham, Ron Smith and participants at the 2010 SGPE conference in Peebles for their helpful comments and suggestions. Alexander Kadow would like to thank M. Hashem Pesaran for making available the GAUSS routines and L. Vanessa Smith for computational support.

${ }^{\dagger}$ corresponding author: Department of Economics, Adam Smith Building, Glasgow, G12 8RT, United Kingdom; Tel: +44 (0)141-330 2592; Fax: +44 (0)141-330 4940; a.kadow.1@research.gla.ac.uk 


\section{Introduction}

Long before the introduction of a single European currency, the notion of potential asymmetries within the European Monetary System (EMS) startled a debate both between academics and central bankers. The claim was that other members' central banks surrendered their monetary sovereignty to the German Bundesbank by mimicking German monetary policies with an eye towards keeping their domestic currency values stable vis-à-vis the Deutschmark (DM).

This so-called "German Dominance Hypothesis" (henceforth GDH) received considerable attention in the empirical exchange rate literature. Although theory would support the idea of an asymmetric monetary system (Barro and Gordon (1983); Giavazzi and Pagano (1988)), conclusive and robust empirical evidence is rather scant. The econometric approach was typically based on short-run nominal money market rates and identified asymmetries in the EMS in terms of Granger causality. The monetary system was considered asymmetric in the strict sense if there was evidence for unidirectional causality from Germany to the other EMS members (Uctum, 1999). Several authors (Katsimbris and Miller (1993); Hassapis et al. (1999)) added an extra-European dimension and tested how monetary innovations from the rest of the world (ROW), proxied by the US, were transmitted into the EMS. International asymmetry in this broader sense implied that the ROW only affected the other EMS countries through its impact on German money market rates. German Dominance would then only be fulfilled if both forms of asymmetry could not be rejected simultaneously.

German monetary leadership in the EMS has been investigated empirically by a number of authors. Fratianni and von Hagen (1990), von Hagen and Fratianni (1990) and de Grauwe (1989) find no statistical evidence for the notion of German Dominance (at least not in the strong form of unidirectional causality). Their results rather support the idea of multidirectional linkages within the EMS, attributing the Bundesbank an important, yet not dominant role. Karfakis and Moschos (1990), on the other hand, fail to reject the GDH. ${ }^{1}$ They conclude that German interest rates Granger-cause other EMS members' rates in a bivariate setup.

We believe, however, that previous empirical results on the GDH should be taken with a grain of salt due to several limitations in the econometric methodology employed at that time. In particular, the notion of cointegration was not well established and often not tested for at all. Commonly used vector autoregressive (VAR) specifications in first differences are hence likely to yield biased estimates. Also, Granger causality tests suffer from a timing problem since they are unable to distinguish between the short and the long run.

These issues are addressed properly by Kirchgässner and Wolters (1993). They formulate and test the GDH in a multivariate cointegration framework and find evidence for German Dominance by imposing appropriate restrictions on loading co-

\footnotetext{
${ }^{1}$ Giavazzi and Giovanni (1987) and MacDonald and Taylor (1991) are amongst others to support the idea of German Dominance as well.
} 
efficients and the cointegrating vector. The debate back then was essentially framed in terms of the loss of monetary independence (a cost). The alternative notion of convergence seems more appropriate for today's enlarging eurozone. Similar tests of interest rate linkages have to our knowledge not yet been conducted for the euro area vis-à-vis other European Union (EU) members that have the ambition to join. ${ }^{2}$

The institutional environment has changed rather importantly with the creation of a European Economic Monetary Union (EMU) and the creation of the European Central Bank (ECB). Whereas the empirical evidence on German Dominance in the pre-euro era (and the loss of monetary autonomy of national central banks to the Bundesbank) remains a matter of debate, the ECB nowadays acts as the single legal body that is responsible for conducting monetary policy for the whole euro area. The monetary system is hence by definition symmetric upon making abstraction of governance issues within the ECB. The question of greater cooperation of national central banks as opposed to following a hegemonic player no longer applies in the absence of the " $N-1$ problem". ${ }^{3}$ For countries outside EMU, however, potential ECB leadership may be desirable from a convergence perspective but may equally be problematic in the face of domestic or global shocks over a shorter horizon. This also raises the question of the transmission of EMU shocks to those countries.

The main contribution of this paper consists in reformulating the GDH in terms of the current eurozone and non-eurozone countries that are on the brink of accession; that is, we introduce the so-called Euro Dominance Hypothesis (henceforth $\mathrm{EDH})$. Our monetary convergence analysis focuses on the transitional economies from Central and Eastern Europe (CEE) for several reasons. First, the process of European integration received a fresh impetus with the EU eastern enlargement. This, in turn, revitalised research into issues such as the endogeneity of optimum currency areas, the potentially increasing heterogeneity in monetary policy transmission channels, the impact on movements of goods, capital and labour across borders, etc. ${ }^{4}$ Second, unlike countries such as the United Kingdom or Denmark, the Treaty on European Community requires newly joining EU member states to eventually introduce the euro. ${ }^{5}$ European monetary integration is therefore defined within the context of this paper as a process of interest rate convergence with the eurozone that culminates into the introduction of the euro as single currency. This implies that national central banks irrevocably fix their national currencies with the euro at some predetermined rate and hand over their monetary autonomy to the ECB. Although national central banks can still influence the decision-making within the

\footnotetext{
${ }^{2}$ Feridun (2006) extends the geographic scope of the GDH by testing for linkages between the Czech Republic and Slovakia vis-à-vis Germany from 1991 to 2004. However, the problem with this analysis is that the Bundesbank has no longer been in charge of conducting independent monetary policy since 1999.

${ }^{3}$ See Fratianni and von Hagen (1992) for a lucid discussion of the cooperative versus the disciplinary interpretation of the EMS.

${ }^{4}$ See for instance Angeloni et al. (2005) or de Grauwe and Mélitz (2005) for a further discussion.

${ }^{5}$ From the original ten CEE member countries only Slovenia (in 2007) and Slovakia (in 2009) so far have met the Maastricht convergence criteria which allowed them to join the eurozone. The CEE countries which yet need to become part of the euro area are in alphabetical order: Bulgaria, the Czech Republic, Estonia, Hungary, Latvia, Lithuania, Poland and Romania.
} 
ECB, conducting independent monetary policies to stabilise the domestic economy is no longer possible.

The current situation of CEE countries outside the eurozone trying to bring their domestic monetary policy and currencies more in line with the ECB policies bears similarities with the EMS situation. In the 80's and 90's the DM and the Bundesbank were considered the major currency and the "leading" central bank within the EMS. The DM was widely used outside Germany, particularly in CEE countries. About 30-40\% of the currency in circulation was held abroad according to a Bundesbank study (Seitz, 1995). A similar degree of currency substitution for the euro can also be identified in some CEE economies (Dvorsky et al., 2008). Both ECB and Bundesbank moreover share a similar constitution. The GDH was generally motivated by the credible low-inflation path of the Bundesbank. Given these historial and institutional similarities, it seems natural to consider the euro and the ECB as a continuation of the DM and the Bundesbank, respectively, and to upgrade models developed for the analysis of the EMS to today's environment.

Our testing framework not only offers an upgrade in the institutional dimension but also on the methodological level. While reduced from specifications such as the vector error correction model (VECM) employed by Kirchgässner and Wolters (1993) may be considered theory-averse, large-scale macroeconometric models are by their very nature computationally intense and are thus typically only developed by major policy institutions. We test for monetary convergence between EMU and non-EMU countries using a rather novel global vector-error correcting modelling approach due to Pesaran et al. (2004) and furthered by Dees et al. (2007).

Global VAR (GVAR) modelling may be considered an attempt to unite more data-driven European approaches with the more theory-driven American take on econometrics. ${ }^{6}$ In contrast to cointegrated systems as advanced most notably by Johansen (1995), some variables are treated as structurally exogenous based on theoretical considerations. This procedure allows for richer dynamic specifications and a more efficient analysis of macroeconomic data, particularly for relatively short time periods (Pesaran et al., 2000).

The GVAR approach seems to be particularly suitable for the case of small open economies, where it is plausible to assume that variables such as foreign prices are exogenous. Loosely speaking, variables are considered weakly exogenous in this context if they only affect domestic variables contemporaneously but are not affected by domestic deviations from the long-run equilibrium. Granger and Lin (1995) refer to weakly exogenous variables as "long-run forcing" in the presence of cointegration and as such this notion is very much different from "Granger causality" which commonly framed the empirical investigation of the GDH.

While the GDH suggests that the Bundesbank dictated monetary policies in the EMS, our idea of the EDH implies that the ECB now takes up a similar role in the enlarging $\mathrm{E}(\mathrm{M}) \mathrm{U}$. The GVAR approach allows for a coherent formulation of the $\mathrm{EDH}$. It fully exploits the information set and at the same time reflects the structural

\footnotetext{
${ }^{6}$ Also see Hoover et al. (2008) and the references therein for a discussion on this controversy.
} 
underpinnings of monetary integration in Europe. It will be interesting to see to what extent the EDH testing results are sensitive to the prevailing exchange rate regime in the CEE countries. The main goal of this article is to investigate whether the EDH not only applies to countries such as Bulgaria, Estonia or Lithuania which have adopted a unilateral currency board arrangement with the euro (CBA) but also to explicit inflation targeters such as Poland.

The paper is structured as follows. Section 2 discusses in more detail alternative ways of formulating the EDH. We present the data and test the EDH in terms of the preferred GVAR model in Section 3. Section 4 investigates how the findings on Euro Dominance are affected by global shocks. Section 5 concludes.

\section{Formulating the EDH}

\subsection{The EDH in terms of a VECM}

In line with the state of econometric advancement at that time the conventional way of investigating the GDH was by means of Granger causality tests, typically in bivariate VAR systems in first differences. Kirchgässner and Wolters (1993) were the first to properly account for cointegration by formulating the GDH in terms of a VECM which combines short-run deviations with long-run equilibrium co-movements in a multivariate setting. We could follow their approach and write in the presence of cointegration the reduced form VECM(p) of order $p$ for the $N$ countries as

$$
\Delta \boldsymbol{R}_{\boldsymbol{t}}=\boldsymbol{\Phi} \boldsymbol{d}_{\boldsymbol{t}}+\boldsymbol{\alpha} \boldsymbol{\beta}^{\prime} \boldsymbol{R}_{t-\mathbf{1}}+\sum_{k=1}^{p-1} \boldsymbol{\Pi}_{\boldsymbol{k}} \boldsymbol{\Delta} \boldsymbol{R}_{t-k}+\varepsilon_{\boldsymbol{t}}
$$

where $\varepsilon_{t}$ is a $N$-dimensional zero mean white noise process with positive definite covariance matrix and $\boldsymbol{\Phi}$ includes deterministic terms such as dummies. $\boldsymbol{R}_{\boldsymbol{t}}$ are the domestic nominal interest rate series. The parameter matrices $\boldsymbol{\alpha}$ and $\boldsymbol{\beta}$ are of dimension $(N \times r)$ with $r$ representing the number of cointegrating relations. The VECM is a restricted VAR in that it adds the cointegration space $\boldsymbol{\Gamma}=\boldsymbol{\alpha} \boldsymbol{\beta}^{\prime}$ which identifies the long-term integration process: $\boldsymbol{\beta}$ quantifies the cointegrating relations and $\boldsymbol{\alpha}$ contains the loading coefficients which attach weights to the longrun equilibrium relations. The short-run interest rate dynamics are described by $\Pi$. The VECM is sometimes also referred to as Cointegrated VAR (CVAR) and obviously nests the first-differenced VAR.

European monetary integration was earlier defined as a process that has both short-term and long-term aspects. We assume for the remainder that all CEE countries have the intention to join EMU over the long run, given the absence of an opt-out clause. One natural way to identify Euro Dominance is therefore to analyse convergence in terms of $\boldsymbol{\Gamma}$. The EDH may be thought of consisting of the following hypotheses in reference to Kirchgässner and Wolters (1993): CEE Dependence, Euro Independence, CEE Insularity and Global Insularity - all of which could easily be tested by imposing appropriate exclusion restrictions on $\boldsymbol{\alpha}$. 
The notion of CEE Dependence simply suggests cointegration between CEE interest rates and euro rates, whereas Euro Independence implies weak exogeneity of the euro area with respect to CEE countries. We could not reject the EDH in its strong form if we found evidence for the first two conditions which would identify euro rates as the common stochastic trend. The notion of CEE Insularity is meant to enrich the argument by allowing for feedback relations in a multivariate context. The other insularity condition lifts the EDH on a global level, thereby accounting for the increasing interlinkages across countries and allowing for feedback with the ROW.

While the VECM approach allowed us to formulate the EDH in a consistent manner, economically meaningful normalisations of the cointegrating vector would crucially hinge on the existence of a common stochastic trend. Cointegration tests for large $N$ but relatively short time dimension may be prone to size distortions, however. The most natural way of dealing with this "curse of dimensionality" seems to be to first investigate interest rate linkages on a domestic level, before analysing all series in a combined system. This is the essence of GVAR modelling we discuss next.

\subsection{The EDH in terms of a GVAR}

Our proposed approach in formulating and testing the EDH is mainly empirical in nature but it also has some structural underpinnings. Suppose there are two blocs of countries $(C E E$ and $E M U)$ and both blocs have their own independent central banks. $E M U$ is a large economy and follows a common monetary policy, whereas $C E E$ consists of several more disjoint small open economies. Monetary policy makers in $C E E$ are as a consequence somewhat more heterogeneous in their choice of operating procedures but share a common overall objective of ultimately becoming part of $E M U$.

We may conceptualise the situation in $C E E$ by means of the following policy rule:

$$
R_{i t}=G(L) z_{t}
$$

where $\boldsymbol{R}_{i t}$ represents the vector of policy instruments in a particular $C E E$ country (typically short-term interest rates or foreign reserves), $\boldsymbol{G}(\boldsymbol{L})$ is a vector polynomial in the lag operator $L$ and $z_{t}$ contains policy-relevant endogenous and exogenous variables, including short-term interest rates in $E M U{ }^{7}$ Specifying some sort of reaction function, however, might not only be limited by data availability and reliability but would also lead us to exclusively centre the analysis around short-run central bank behaviour. Our proposed error-correcting specification is richer: It captures shortrun deviations but models interest rate convergence in particular under a long-run equilibrium perspective.

\footnotetext{
${ }^{7}$ Obviously, if euro area interest rates would not matter to the policy rule in $C E E$ the corresponding parameter value $g_{i}$ in the parameter vector $\boldsymbol{g}$ was just zero. Other variables which may be part of $z_{t}$ are output gaps or exchange rate differentials between the two blocs.
} 
The Maastricht criteria of stable nominal exchange rates but at the same time low and stable inflation rates describe the relevant benchmarks for monetary convergence. CEE central banks have moved towards the extremes of possible exchange rate arrangements over the last decade. The Bank of Latvia for example recently pegged the lat tightly with the euro, only allowing for much smaller fluctuations than stipulated in the Exchange Rate Mechanism II (ERM II) which essentially replaced the former EMS. Other national central banks announce explicit inflation targets and allow their exchange rates to float freely. Table 1 gives an overview of the prevailing monetary policy regime as of the end of 2009. The stabilising effects on the exchange rate from inflation targeting or active exchange rate fixing are apparent from market data. ${ }^{8}$ This seems to suggest that the exchange rate arrangement in itself is not decisive for successful EMU entry, although there is some evidence that greater flexibility facilitates compliance with the Maastricht criteria (Lewis, 2009).

Table 1: Overview of monetary policy frameworks in CEE

\begin{tabular}{ll}
\hline & monetary policy framework \\
\hline Bulgaria & CBA \\
Czech Rep. & floating; inflation targeting \\
Estonia & CBA; ERM II \\
Hungary & floating; inflation targeting \\
Latvia & hard peg; ERM II \\
Lithuania & CBA; ERM II \\
Poland & floating; inflation targeting \\
Romania & floating; inflation targeting \\
\hline
\end{tabular}

Sources: Public information by the ECB and national central banks in $C E E$ CBA stands for unilateral currency board arrangement with the euro; ERM II indicates membership in the Exchange Rate Mechanism II

The GVAR approach allows for considering various real and nominal variables at a time. In line with the structural underpinnings and reported descriptive evidence we resist the temptation of extending the analysis further and confine ourselves to short-term nominal interest rates. This not only allows for a more transparent mapping to the VECM (a crucial methodological contribution of our paper) but those also seem to be the most reliable measure of monetary convergence for the enlarging euro area. Coricelli et al. (2006) study the transmission of monetary policies in CEE countries and find empirical evidence for a complete passthrough from domestic monetary policy key rates to short-term money market rates. The CEE banking industry has undergone substantial reforms towards market-based structures during the 90 's. In contrast to bond, equity and derivative markets, the financial sector currently matches EMU standards and can no longer be considered "underdeveloped".9 Previously state-owned banks were privatised to establish a so-called two-tier bank-

\footnotetext{
${ }^{8}$ See figure A.1. A notable exception may be the Hungarian forint which has been subject to speculative attacks lately.

${ }^{9}$ See Schadler et al. (2005) for more detailed evidence.
} 
ing system consisting of an independent central bank and several private commercial banks. The process of market liberalisation led to the removal of interest rate ceilings on credits and lowered entry barriers for private domestic and foreign banks. Accounting standards, commercial and bankruptcy law as well as banking supervisory and regulatory procedures were put in place to meet the changed market structures (Dickinson and Mullineux, 2001).

Given the state of development of the financial sector in CEE, convergence of monetary policies may therefore be best identified on money markets. If national central banks outside the eurozone mimicked the ECB's path, it may be conjectured that this is reflected in the CEE domestic money markets, i.e. CEE and EMU interbank rates are expected to be cointegrated. GVAR modelling (Pesaran et al. (2004), Dees et al. (2007)) tests for cointegration first in country-specific systems before combining all error-correcting terms in a global model. One may thus view the proposed framework as an attempt to consolidate the different approaches used during EMS times to examine the GDH. This two-stage approach offers an alternative, more structural, way of investigating the EDH.

A crucial difference between the VECM and the GVAR related to these structural underpinnings lies in the way weak exogeneity is introduced. Whereas in the VECM weak exogeneity is tested for by imposing exclusion restrictions on estimated parameters, particular variables in the GVAR specification (typically foreign quantities) are treated as weakly exogenous from the outset. We could, of course, also condition on weakly exogenous variables in the VECM. As we shall see below, however, the GVAR allows for a coherent analysis of impulse responses within a global system and thus accounts for the interlinkages across the partial models.

Each country-specific error-correcting model contains both domestic and foreign variables. The latter ones are treated as long-run forcing in the sense of Granger and Lin (1995) without necessarily ruling out short-run feedback from the lagged variables. We conjecture euro rates to be (weakly) exogenous to CEE countries. We also introduce global influences, proxied by US interest rates. We have $N=10$ countries, where EMU is the reference country. We therefore denote euro rates by $R_{0 t}$ and dollar rates by $R_{t}^{*}$. We index CEE rates by $i=1, \ldots, n$ with $n=8$.

We model the EDH in terms of the GVAR as follows. We introduce two sets of $V A R X^{*}\left(p_{i}, q_{i}\right)$ models for each country bloc, CEE and EMU, where $p_{i}$ and $q_{i}$ refer to the lag order of the domestic and the foreign rates, respectively. The CEE-system looks as follows

$$
\boldsymbol{\Theta}_{\boldsymbol{i}}\left(L, p_{i}\right) \boldsymbol{R}_{i t}=\boldsymbol{a}_{i 0}+\boldsymbol{\Lambda}_{\boldsymbol{i}}\left(L, q_{i}\right) \boldsymbol{R}_{0 t}+\boldsymbol{\varepsilon}_{i t}
$$

and for EMU we have

$$
\Theta_{0}\left(L, p_{i}\right) R_{0 t}=a_{0}+\Lambda_{0}\left(L, q_{i}\right) R_{t}^{*}+\varepsilon_{0 t} .
$$

All idiosyncratic shocks $\varepsilon_{t}$ are assumed to be i.i.d. Note that (2) and (3) are simply reduced form VAR models augmented by (weakly) exogenous foreign variables which nest standard unrestricted VAR processes if $\boldsymbol{\Lambda}\left(L, q_{i}\right)=\mathbf{0}$. The CEE model suggests that CEE countries are small open economies which take interest rates in the large 
economy EMU as exogenously given. US interest rates affect CEE markets indirectly via EMU rates. US interest rates are thus treated under the null as globally exogenous to reflect the idea of the US being a proxy for the ROW.

The EDH can now be stated as a joint hypothesis consisting of three legs:

\section{- (I) CEE Dependence:}

There is evidence for cointegration between $R_{i}$ and $R_{0}$.

- (II) Euro Independence:

$R_{0}$ is indeed weakly exogenous to $R_{i}$.

- (III) Global Independence:

$R^{*}$ is weakly exogenous to $R_{0}$.

Our definition of the EDH implies several adjustments compared to the original GDH specification. In particular, we no longer conjecture any form of "insularity" which seems to be an awkward notion, given the size of the CEE countries and the degree of cooperation and coordination within the EU. ${ }^{10}$ The way we formulate the $\mathrm{EDH}$ rather reflects two developments the EU faces: globalisation and integration. Globalisation particularly refers to linkages outside Europe with the ROW as captured by condition (III). Integration is more related to inner-European issues, most notably the eastern enlargement of $\mathrm{E}(\mathrm{M}) \mathrm{U}$ which conditions (I) and (II) examine. In a later step, in section 4, we shall elaborate on the idea of globalisation and the impacts on the EU and link (2) with (3).

\section{Testing for Euro Dominance}

\subsection{Data}

Our study is based on 3-month interbank rates obtained from Eurostat. Since Bernanke and Blinder (1992)'s seminal paper short-term money market rates have become the commonly accepted proxy for modelling monetary policy behaviour and transmission in many economies. Given our focus on long-term aspects of monetary convergence and given the noise and jumps present in daily interest rate movements, we opted for a monthly frequency. The dataset ranges from January 2000 to August 2009. Accession negotiations with the CEE countries started already in the late 90 's such that market expectations and interest differentials in line with the idea of uncovered interest rate parity are likely to reflect any signs of convergence early on. ${ }^{11}$

\footnotetext{
${ }^{10}$ Also see Kadow (2007) who finds evidence for multilateral links (network effects) both between $\mathrm{CEE}$ countries and with the eurozone using a multivariate cointegration approach.

${ }^{11}$ Ideally one would like to initiate the data in 1999 . We refrained from doing so due to a considerable amount of missing values for some countries in that period.
} 
Figure 1 shows the CEE money market series in levels. Money market rates for the eurozone and the US are added for completeness and for sake of comparison. The figure seems to suggest that short-term interest rates are converging indeed. ${ }^{12}$ All interbank rates display a sharp increase towards the end of 2008 which perfectly coincides with the credit crunch. Interestingly, past CEE interest rate fluctuations have often been much more severe than these end-of-sample spikes. Romania or Poland, for example, experienced interbank rates that were up to 10 times higher than their end-of-sample values.

Figure 1: Monthly observations of 3-month money market rates

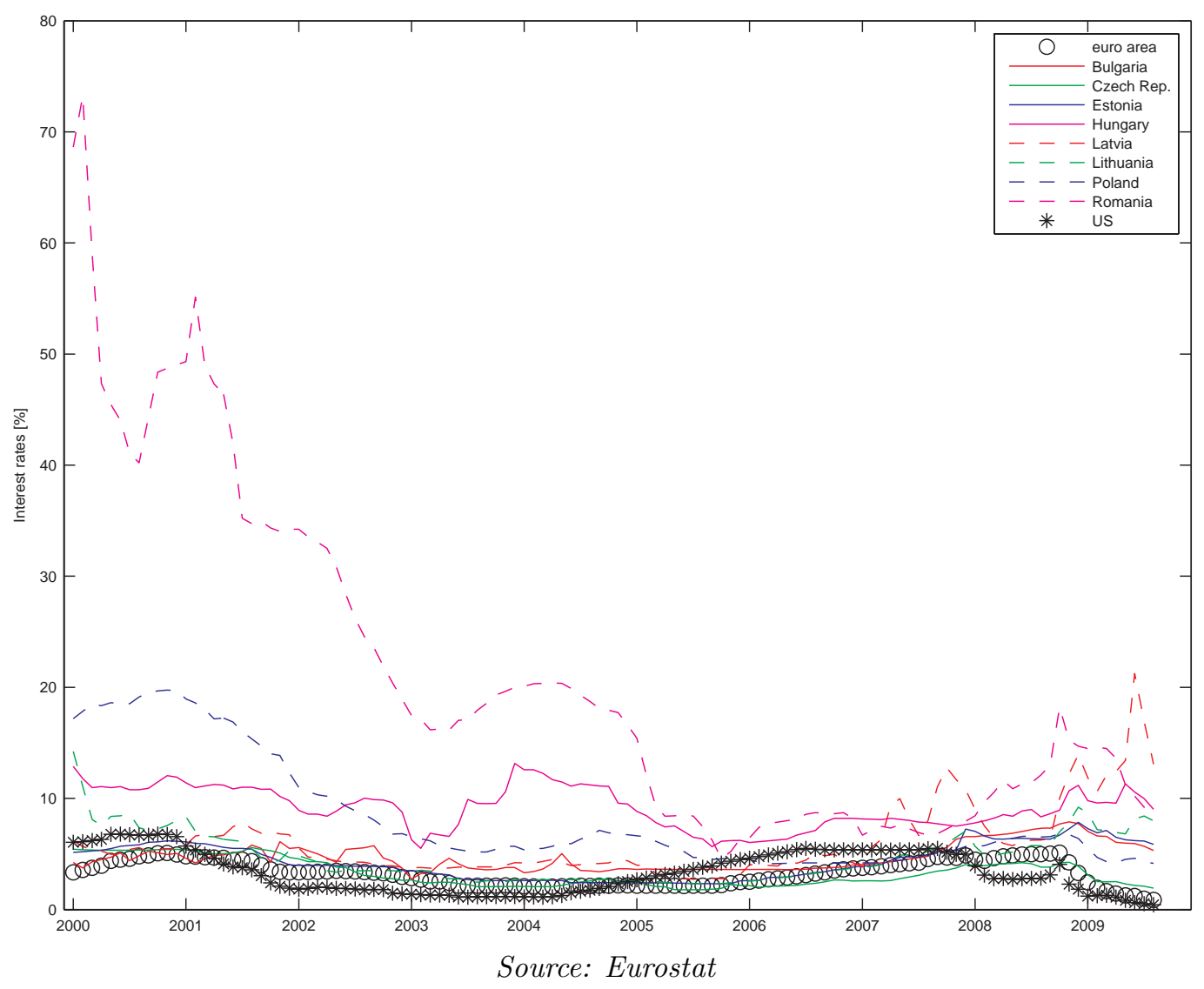

Figure 1 is clearly suggestive of a converging pattern. Graphs, however, can be misleading and a formal analysis is called for. Our proposed framework obviously requires variables to be integrated of order 1, I(1), even though the GVAR approach is flexible enough to accommodate stationarity. We employ the standard augmented Dickey-Fuller (ADF) regressions to test for the presence of unit roots in the series:

$$
\Delta R_{t}=\mu+\gamma R_{t-1}+\sum_{k=1}^{p} \delta_{k} \Delta R_{t-1}+\varepsilon_{t} .
$$

\footnotetext{
${ }^{12}$ We also report the individual series in figure A.2 and in differenced form in figure A.3 to account for the substantial initial spread between some CEE interest rates and euro rates.
} 
On the basis of the graphical analysis we decided not to include deterministic trends in the Dickey-Fuller regressions. As usual, we test the null hypothesis of a unit root, $H_{0}: \gamma=0$, against the alternative that the time series is stationary, or $I(0)$, $H_{1}: \gamma<0$. We conducted the tests at different levels of augmentation, up to a quarter. The lag length was chosen using the Akaike Information Criterion (AIC). Results are reported in table B.1 and suggest that all series are $I(1)$ at the $5 \%$ significance level.

\subsection{Empirical results}

Having established that the cointegrating framework is sensible we proceed with testing the EDH. We first specify the lag structures of (2) and (3). Table 2 reports the lag order of the individual country models. The length selection is performed using the AIC which suggests that a $\operatorname{VARX}(2,1)$ suffices for most CEE country models. ${ }^{13}$ Subject to residual-based specification tests we decided to treat EMU and the US symmetrically with $p_{i}=q_{i}=2$.

Table 2: $\operatorname{VARX} X^{*}\left(p_{i}, q_{i}\right)$ order based on $A I C$.

\begin{tabular}{lcc}
\hline Country & $p_{i}$ & $q_{i}$ \\
\hline Bulgaria & 1 & 1 \\
Czech Rep. & 1 & 1 \\
Estonia & 2 & 1 \\
Hungary & 2 & 1 \\
Latvia & 2 & 1 \\
Lithuania & 2 & 1 \\
Poland & 1 & 1 \\
Romania & 2 & 1 \\
euro area & 2 & 2 \\
\hline
\end{tabular}

Stacking endogenous and exogenous variables in $\boldsymbol{z}_{t}$ and after some reparameterisations we obtain the $\operatorname{VECM} X^{*}\left(p_{i}-1, q_{i}-1\right)$ :

$$
\Delta R_{i t}=c_{i 0}+\alpha_{i} \beta_{i}^{\prime} z_{i, t-1}+\sum_{k=1}^{p-1} \Psi_{k} \Delta z_{i, t-k}+\sum_{k=1}^{q-1} \Lambda_{k} \Delta \widetilde{R}_{i, t-k}+\varepsilon_{i t}
$$

where $\widetilde{R}_{i}$ refers to euro rates in case of $i=1, \ldots, 8$ and to dollar rates for $i=0$.

The EDH can now be tested using (4) in two steps. We start by examining the cointegration properties of the individual country models, followed by an assessment of the weak exogeneity assumption. The country-specific cointegration rank $r_{i}$ is determined using Johansen's trace statistic. We follow Pesaran et al. (2000)'s testing

\footnotetext{
${ }^{13}$ By conditioning on weakly exogenous variables we obtain a richer dynamic structure than in VAR models of the same order which would first need to be rewritten in univariate autoregressive (integrated) moving average (AR(I)MA) representations for comparability (Pesaran et al., 2004).
} 
procedure and restrict the intercept to the cointegrating relations, hereby ruling out linear trends in the data. Critical values are simulated based on 10,000 replications.

Detailed cointegration test results can be found in table B.2. Euro and dollar rates cointegrate but there is also strong evidence for cointegration between CEE rates and EMU. Evidence for Bulgaria is slightly weaker but still well within the $10 \%$ level. We failed to establish cointegration between Hungarian and EMU interbank rates. This finding may well be a result of the recent economic turmoil in Hugary as the national central bank had to deal with speculative attacks on the forint. While we may find evidence for Euro Dominance in Hungary in a different information set, we conclude that the EDH is not supported by Hungarian money market rates. ${ }^{14}$

To test for Euro and Global Independence (conditions (II) and (III)) we assess the pivotal weak exogeneity assumption which in econometric terms may be considered a test for misspecification. We test for the significance of the estimated error-correcting term, $E C T_{i, t-1}$, in the marginal model for $\widetilde{R}_{i t}$ following Dees et al. (2007). For example, to test for weak exogeneity of EMU interest rates in the Bulgarian country model $(i=1)$ we need to evaluate the null hypothesis that $\gamma_{1}=0$ in the auxiliary regression:

$$
\Delta R_{0 t}=\mu_{1}+\gamma_{1} E C T_{1, t-1}+\sum_{k=1}^{s_{1}} \delta_{1, k} \Delta R_{1, t-k}+\sum_{m=1}^{n_{1}} \varphi_{0, m} \Delta R_{0, t-m}+\varepsilon_{1, t},
$$

where we maintain the lag order of the underlying $V A R X^{*}$ by setting $s_{1}=p_{1}$ and $n_{1}=q_{1}$. Results of this standard $t$-test are provided in table B.3 and support the notion of weak exogeneity in all relevant country-specific models.

Table 3: Summary of EDH testing

\begin{tabular}{lccc}
\hline & $(\mathbf{I})$ & $($ II $)$ & $($ III) \\
Country & CEE Dependence & Euro Independence & Global Independence \\
\hline Bulgaria & $\dagger$ & $\dagger$ & $\dagger$ \\
Czech Rep & $\dagger$ & $\dagger$ & $\dagger$ \\
Estonia & $\dagger$ & $\dagger$ & $\dagger$ \\
Hungary & - & - & - \\
Latvia & $\dagger$ & $\dagger$ & $\dagger$ \\
Lithuania & $\dagger$ & $\dagger$ & $\dagger$ \\
Poland & $\dagger$ & $\dagger$ & $\dagger$ \\
Romania & $\dagger$ & $\dagger$ & $\dagger$ \\
\hline
\end{tabular}

$\ddagger$ indicates significance at the $10 \%$ level; $\dagger$ at the $5 \%$ level

Table 3 summarises the empirical results. Overall, we seem to have established strong evidence for the notion of Euro Dominance in the enlarging euro area. With

\footnotetext{
${ }^{14}$ Excluding Hungary improves the stability of the subsequent GVAR analysis. This allows us to model all countries symmetrically despite the relatively small number of countries included and despite the juxtaposition of small with large economies.
} 
the exception of Hungary, domestic CEE money markets are dominated by the euro area over the long run which follows from conditions (I) and (II). The EDH seems to hold in the strong form in the sense that euro rates are weakly exogenous. We also find that dollar rates move independently from the eurozone. US interest rates thus affect CEE countries only via the euro area which confirms condition (III) of Global Independence.

\subsection{Impulse response analysis}

Figure 2: GIRF to country-specific shock
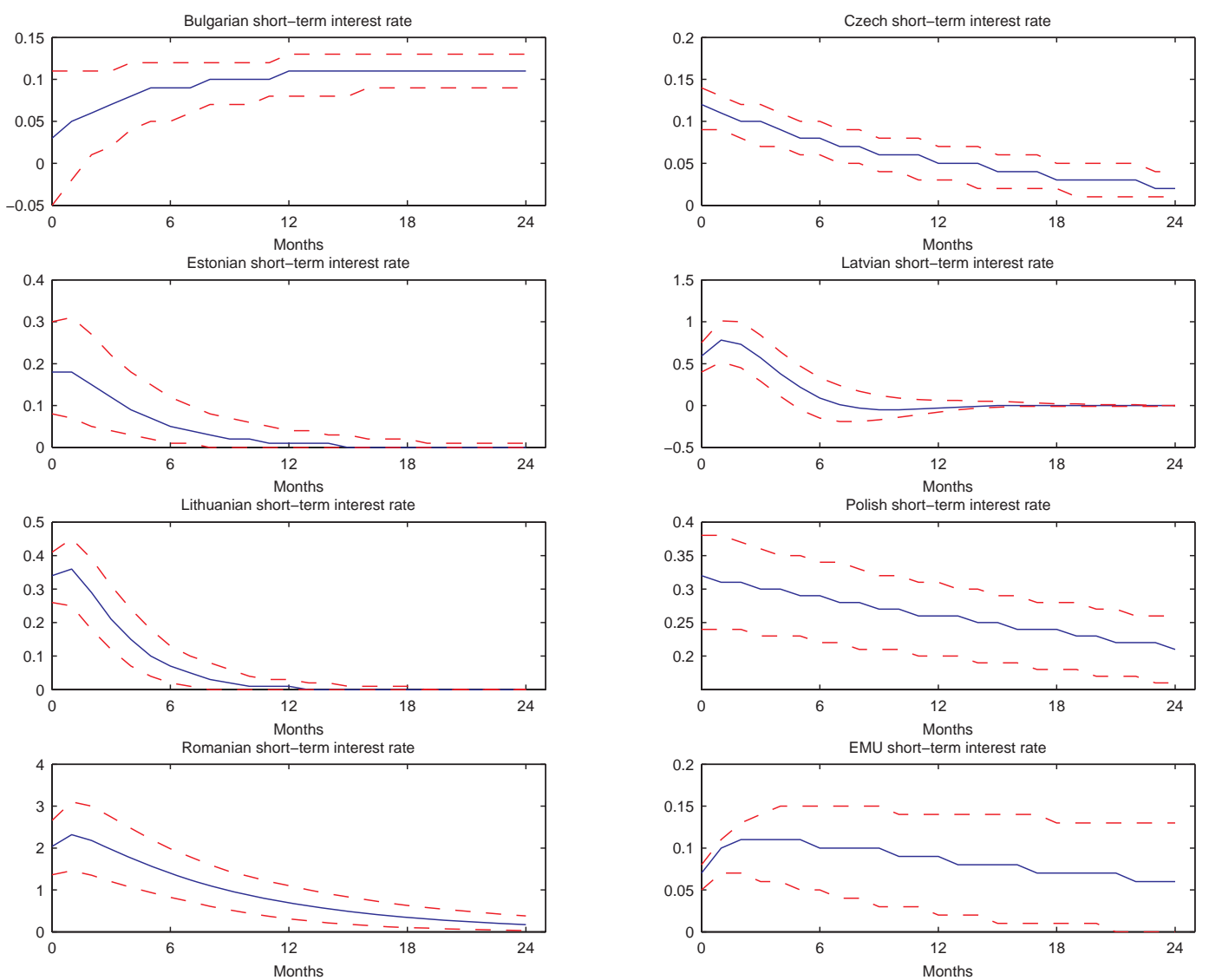

The solid lines plot the country-specific point estimates; the dashed lines show the 95\% confidence intervals which are based on a sieve bootstrap using 5,000 replications.

Any investigation of financial linkages is of little meaning without analysing the transmission of shocks. Based on the empirical evidence for Euro Independence and Global Independence we shock foreign interest rates in the country-specific models and estimate Generalised Impulse Response Functions (GIRFs). We distinguish between the impulse responses arising from an EMU shock on CEE interest rates 
and a ROW shock on EMU interest rates. Both shocks are scaled appropriately to correspond to a rise by one standard deviation of the error variance on impact. Graphical output is summarised in figure 2. The panel in the far lower right corner shows the eurozone impulse response function. The solid lines plot the countryspecific point estimates; the dashed lines represent the $95 \%$ confidence intervals which are based on a sieve bootstrap using 5,000 replications.

The figure illustrates the varying speeds of adjustments of the error-correcting relations over a period of 2 years. The analysis reveals that the impact on interest rates dies out fairly quickly for countries with a tight exchange rate regime (see table 1). Bulgaria's response is fairly persistent which may also be due to its comparatively late introduction of the unilateral CBA (also see the corresponding panel in figure A.1). ${ }^{15}$ Romanian markets react quite strongly on impact but mean-reverting behaviour is apparent. The reverting pattern seems more sluggish for inflationtargeting countries, considering the Polish response to the EMU shock or the EMU response to the ROW shock, respectively.

\section{Economic and financial globalisation and the EDH}

The GVAR model allows for the aggregation of foreign variables to investigate the transmission of shocks on a regional and global level. This appears particularly relevant given the by now large consensus among academics and policymakers that the financial and economic globalisation and market integration also demand for more policy coordination on the supranational level. The current financial and economic crisis constitutes an obvious reminder of that need. We analyse in this section to what extent the evidence on Euro Dominance is affected by such global shocks, providing some preliminary insights on the impact of the recent financial crisis.

Given our particular interest in the efforts of CEE countries to integrate with EMU we may think of domestic CEE money markets as being driven by a weighted average of foreign rates, i.e. other CEE money markets but also EMU and the US. We refer to them jointly as $\boldsymbol{R}_{\boldsymbol{i t}}^{*}$ to indicate the conjectured linkages across markets. Foreign interest rates for each CEE country are constructed using country-specific weights

$$
R_{i t}^{*}=\sum_{j=0}^{N} w_{i j} R_{j t},
$$

where $w_{i j}$ is the weight for CEE country $i$ with respect to country $j$ and $w_{i i}=0$. We experimented with different weighting methods such as simple equal weighting (to reflect the overall converging pattern) or exchange rate weights based on purchasing power parities (the conventional way). The empirical findings established previously seem robust and carry over to the analysis here. We therefore keep on excluding the Hungarian model and index the remaining series from $1, \ldots, n-1$.

\footnotetext{
${ }^{15}$ This and the fact that Bulgaria did not join the EU until 2007 (compared to the first enlargement phase of 2004) may also explain the somewhat weaker evidence for CEE Dependence in Bulgaria.
} 
We again stack domestic and (now weighted) foreign country-specific variables in the vector $z_{i t}$ and introduce the matrix $\boldsymbol{W}_{\boldsymbol{i}}$ which is defined by the country-specific weights. This weighting matrix simply links all domestic models and is needed to solve the GVAR. It can therefore accommodate various weights as long as they are predetermined. Moreover, the analysis is invariant to the ordering of the countries.

Stacking all endogenous variables in $\boldsymbol{R}_{\boldsymbol{t}}$ we can write

$$
\boldsymbol{z}_{i t}=\boldsymbol{W}_{\boldsymbol{i}} \boldsymbol{R}_{\boldsymbol{t}} \quad i=1, \ldots, n-1 .
$$

Using (5) allows us to rewrite (2)

$$
\boldsymbol{A}_{\boldsymbol{i}}(L, p) \boldsymbol{W}_{\boldsymbol{i}} \boldsymbol{R}_{\boldsymbol{t}}=\varphi_{i t}, \quad i=1, \ldots, n-1,
$$

where

$$
\varphi_{i t}=\boldsymbol{a}_{i 0}+\boldsymbol{a}_{i 1} t+\varepsilon_{i t} .
$$

We retain the lag structure of the previously specified country models and stack them together to obtain the $G V A R(p)$ :

$$
\boldsymbol{G}(L, p) \boldsymbol{R}_{\boldsymbol{t}}=\varphi_{t},
$$

where

$$
\boldsymbol{G}(L, p)=\left(\begin{array}{c}
\boldsymbol{A}_{\mathbf{1}}(L, p) \boldsymbol{W}_{\mathbf{1}} \\
\vdots \\
\boldsymbol{A}_{\boldsymbol{n}-\mathbf{1}}(L, p) \boldsymbol{W}_{\boldsymbol{n}-\mathbf{1}}
\end{array}\right)
$$

and

$$
\varphi_{t}=\left(\begin{array}{c}
\varphi_{1 t} \\
\vdots \\
\varphi_{(n-1) t}
\end{array}\right) .
$$

We can solve (7) for all endogenous CEE interest rates simultaneously which allows us to analyse impulse responses across the entire information set. We may think of the $G V A R(p)$ in this context as a regional model of CEE money markets because it links this bloc of countries with both EMU and the ROW, while at the same time allowing for the existence of linkages across CEE economies. The presence of a solution to this system indirectly also provides evidence against the notion of "CEE insularity".

The impulse response analysis so far has implicitly assumed that shocks are not global, i.e. they originate from a particular country or region. While this holds by definition for intra-EU shocks, the financial crisis has demonstrated that there are also shocks that cannot so easily be attributed to a particular country or region. This is in particular due to the strong interconnectedness and global character of the financial market place. We therefore construct a "global" shock which is a weighted average of variable-specific shocks and as such common to all CEE countries in the model. ${ }^{16}$

\footnotetext{
${ }^{16}$ See Pesaran et al. (2004) for further technical details and other applications of this procedure.
} 
Figure 3: GIRF to global shock

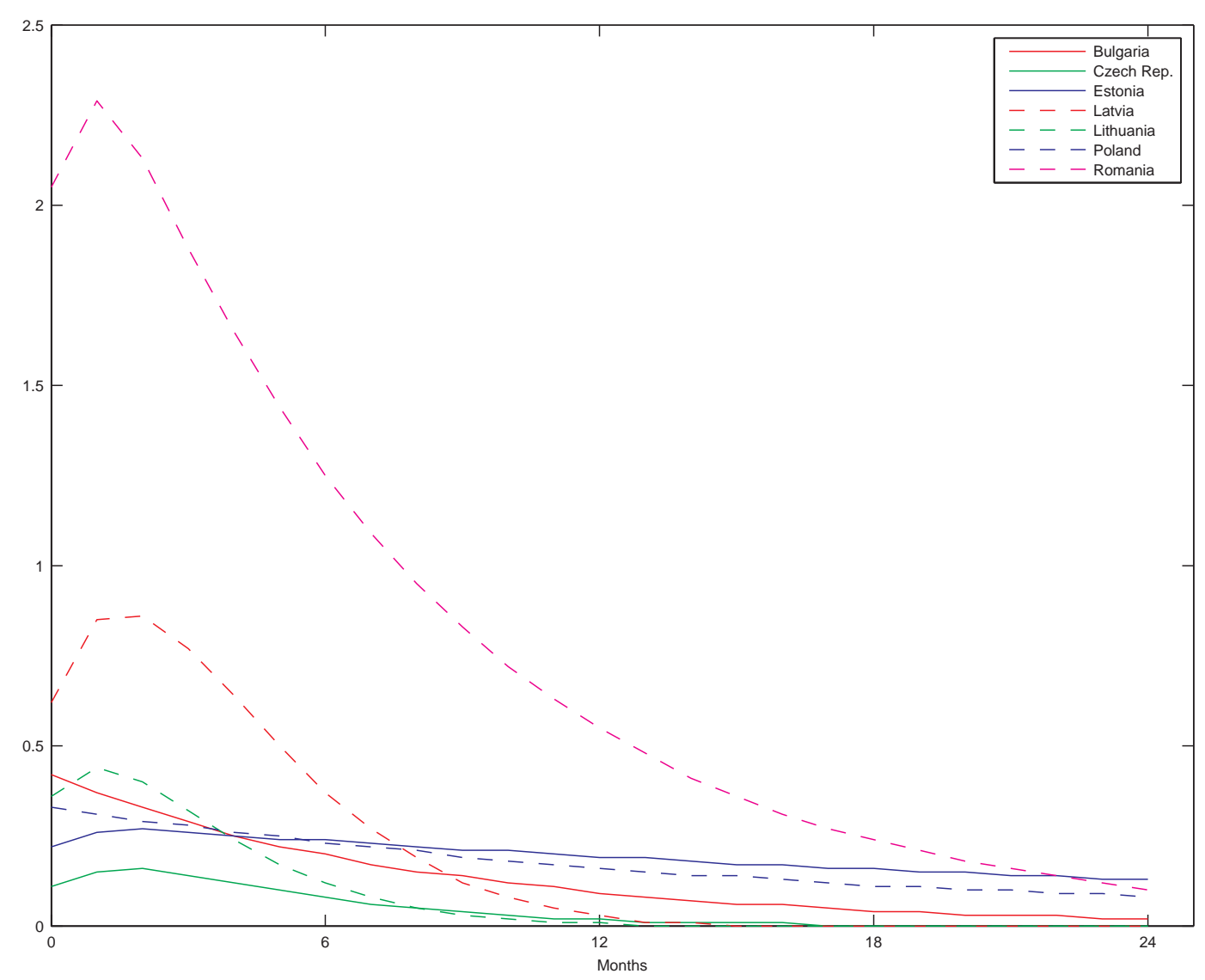

Figure 3 summarises the estimated GIRFs to a one standard error global shock in CEE. The effects through time are qualitatively rather similar to the previous impulse responses to EMU shocks. This finding confirms the predominant role of the euro area in the setting of CEE monetary policies and thus provides further support for the validity of the EDH. It appears one cannot necessarily claim that the occurence of global shocks matters for the process of European monetary integration. It rather seems to be the case that domestic $\mathrm{E}(\mathrm{M}) \mathrm{U}$ events drive the adjustment towards a long-run equilibrium or at least that global shocks are largely "absorbed" by the eurozone and from there transmitted further.

\section{Concluding remarks}

We upgrade in this paper the so-called GDH in two dimensions. First, whereas the earlier literature on the GDH modelled interest rate linkages and causality issues within the former EMS, we reformulate the GDH for the CEE countries vis-à-vis the eurozone. We seek to answer whether the monetary policy implemented by the ECB 
dictates CEE monetary policies. Evidence for this EDH has important implications for the process of European monetary integration as all these countries have committed themselves to eventually introduce the euro and to join the monetary union with a single central bank. Second, we employ the relatively novel methodology of GVAR modelling to investigate convergence and the transmission of external shocks.

Unlike the traditional approaches of testing the GDH that are either bivariate in nature are expressed in terms of high dimensional VECMs, the proposed GVAR model generalises multivariate cointegration analysis to allow for weakly exogenous, structural $I(1)$ variables. This methodology is hence particularly suitable for small open economies. It deals first with error-correcting terms on the country level which allows for richer dynamics and more efficient estimation. One can stack this information in a second step into a global (multi-country) system that can be used to investigate impulse response functions on a "global" level. The proposed approach may hence be considered a consolidation of previous testing procedures.

The EDH is tested as a set of three complementary hypotheses: CEE Dependence, Euro Independence and Global Independence. Our empirical results strongly support the EDH. We find that there is evidence for the notion of Euro Dominance, i.e. CEE Depedence together with Euro Independence, across CEE countries. Domestic CEE policies seem to follow the ECB's monetary policy stance (proxied by money market rates) quite closely irrespective of the prevailing exchange rate arrangement. Country-specific impulse response functions suggest that countries with relatively tight monetary regimes react more strongly to EMU shocks. We reject the EDH for Hungary which may reflect domestic policies dominating over EMU ones. The fact that our procedure reveals differences across economies shows that it has power.

European monetary integration is best understood as an ongoing long-term process. The non-rejection of the EDH is somewhat surprising, given the recent financial turmoil. One may expect that central banks in CEE find it increasingly difficult in the near future to mimic the ECB's policies and to maintain the path of monetary convergence with the euro area. In particular, trying to keep exchange rates, interest rates and inflation rates within the Maastricht ranges on a sustainable basis may become ever more challenging. On the other hand, if the evidence on Euro Dominance was true, CEE central bankers would not lose an independent monetary policy stance through joining EMU but are likely to gain influence in the ECB's common monetary policy decisions. Our analysis suggests that inner $\mathrm{E}(\mathrm{M}) \mathrm{U}$ events rather than external shocks will determine the future of the enlarging eurozone, which speaks in favour of an already advanced state of monetary integration in Europe. 


\section{A Figures}

Figure A.1: Euro exchange rates in terms of domestic CEE currency
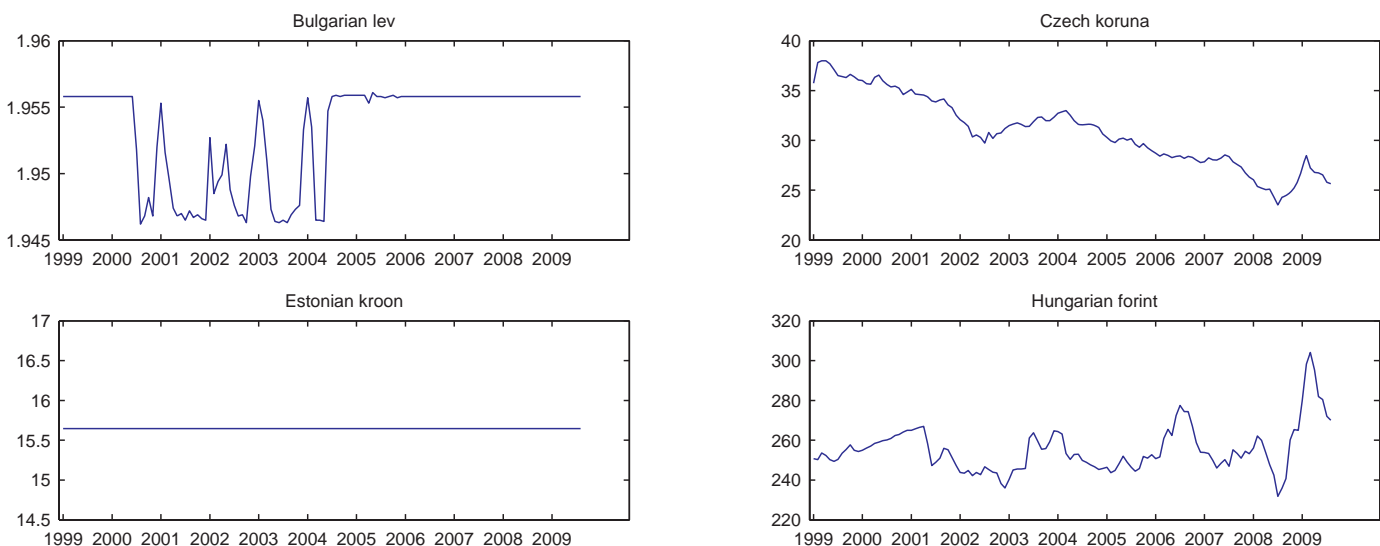

Latvian lats

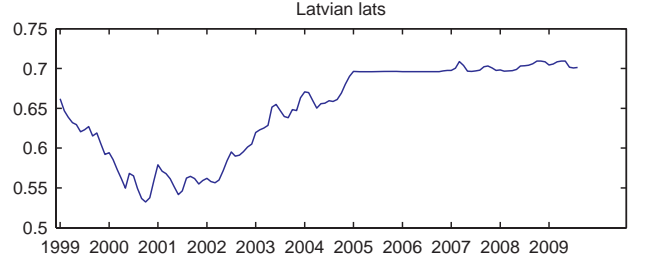

Lithuanian litas
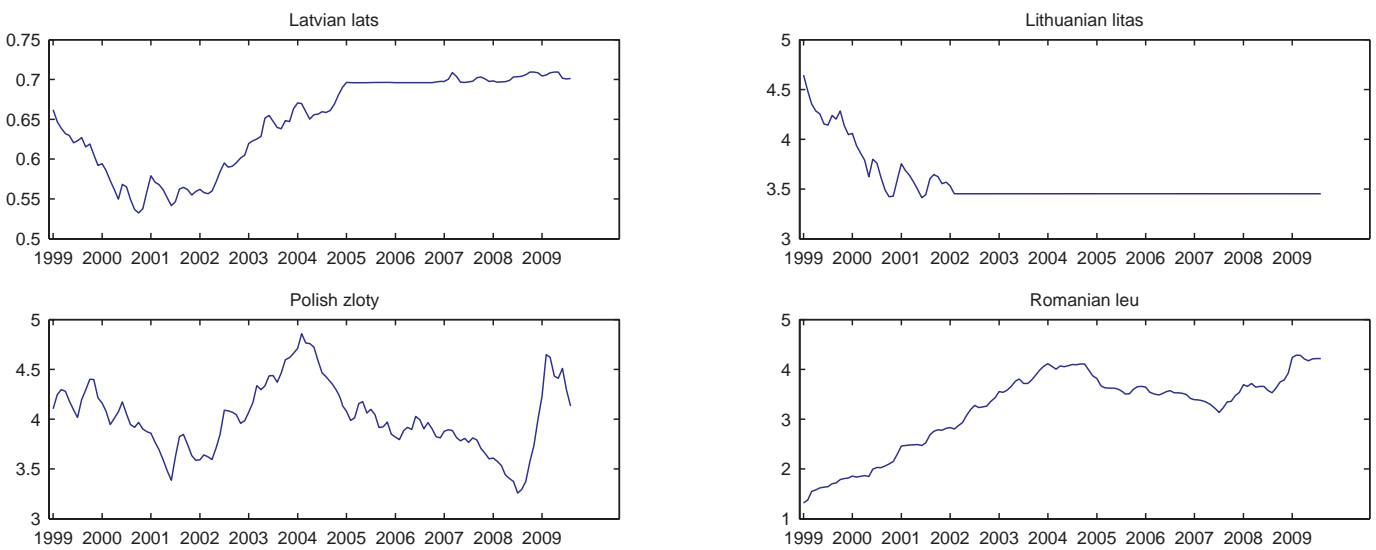

Source: ECB. The data are monthly averages; the old Romanian lei was replaced by the leu on 1 July 2005 
Figure A.2: Levels of individual series
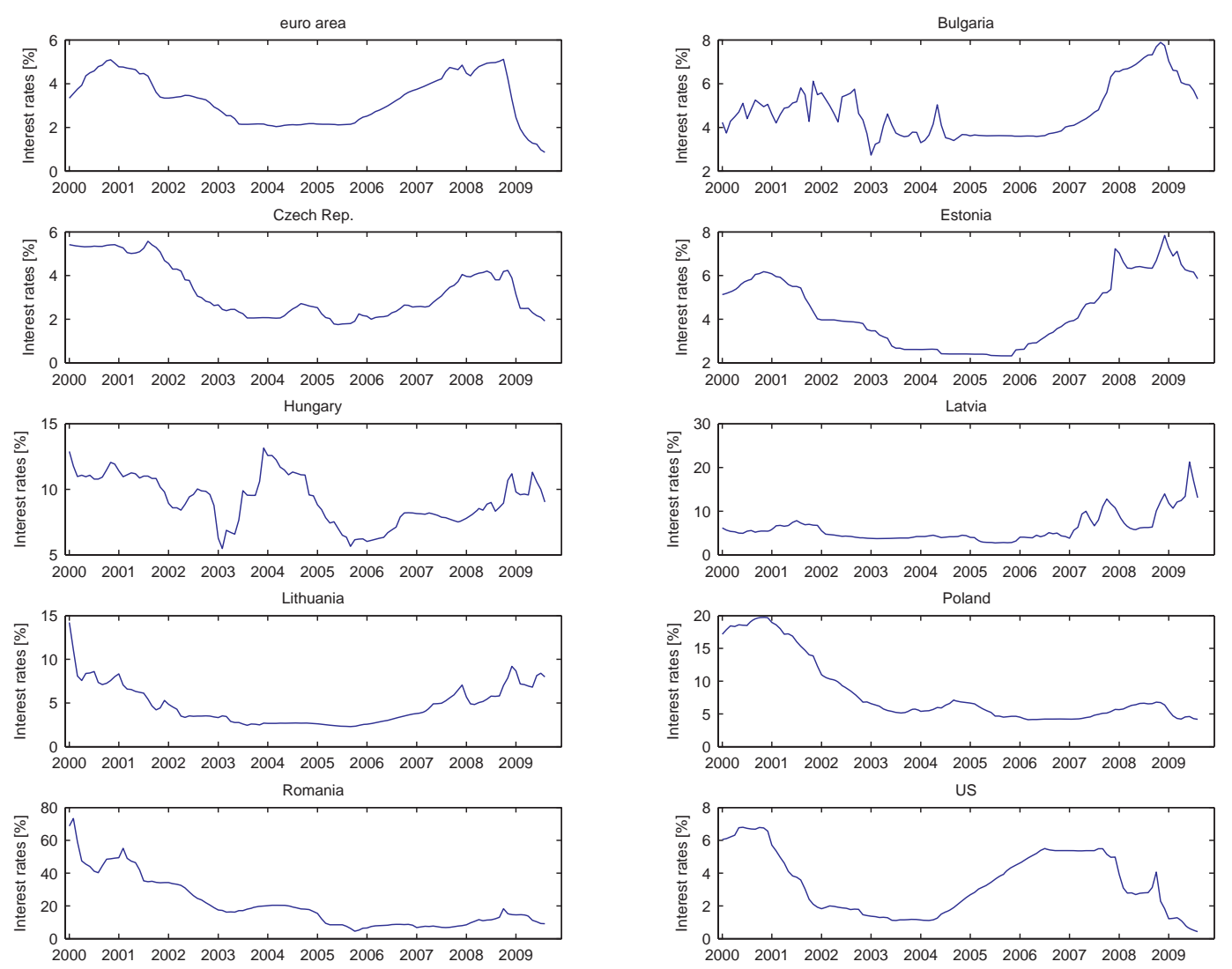
Figure A.3: First differences of individual series

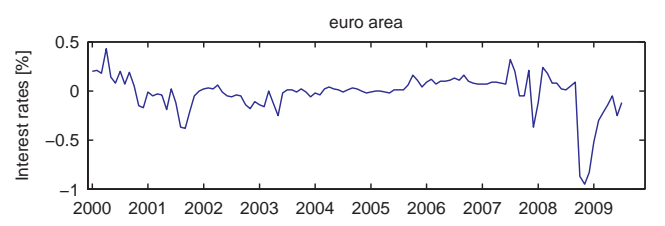

Czech Rep.

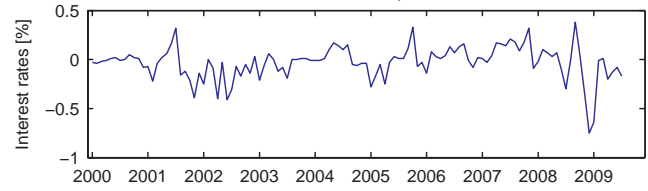

Hungary
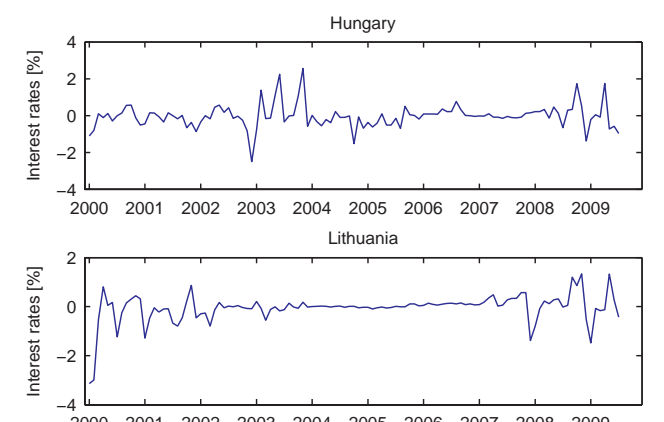
$200020012002 \quad 20032004200520062007 \quad 2008 \quad 2009$

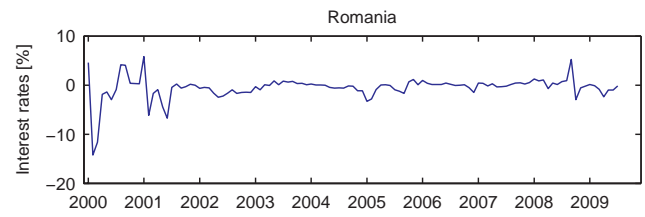

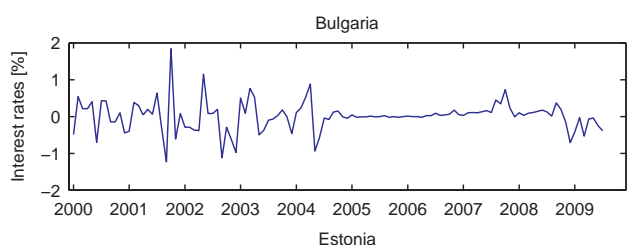

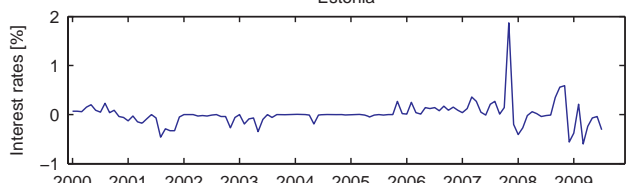

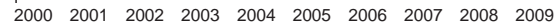
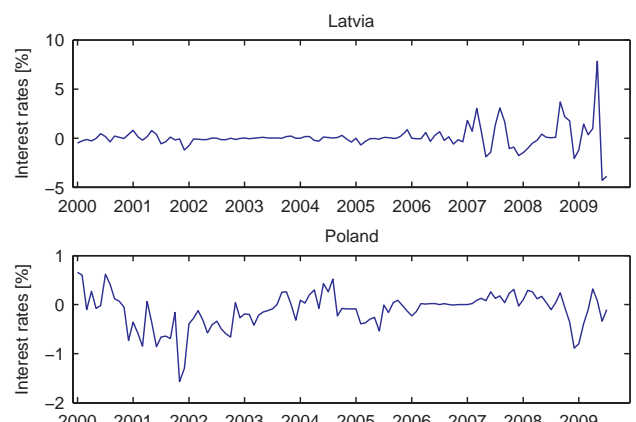

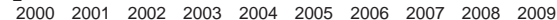

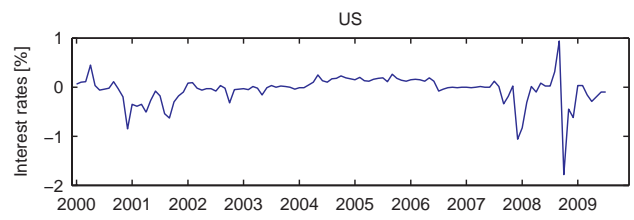




\section{B Tables}

Table B.1: ADF test results

\begin{tabular}{lrrrr}
\hline & $\mathbf{p}=\mathbf{0}$ & $\mathbf{p}=\mathbf{1}$ & $\mathbf{p}=\mathbf{2}$ & $\mathbf{p}=\mathbf{3}$ \\
\hline 1st differences & & & & \\
euro area & $-4.38^{a}$ & -4.35 & -3.52 & -3.88 \\
Bulgaria & -11.20 & -7.76 & -5.84 & $-6.68^{a}$ \\
Czech Rep. & $-5.93^{a}$ & -5.50 & -4.44 & -3.87 \\
Estonia & $-8.59^{a}$ & -7.10 & -4.94 & -4.15 \\
Hungary & $-8.46^{a}$ & -7.35 & -5.85 & -5.10 \\
Latvia & -8.85 & -8.29 & -6.87 & $-6.97^{a}$ \\
Lithuania & -8.12 & $-10.88^{a}$ & -8.09 & -6.78 \\
Poland & $-5.04^{a}$ & -4.18 & -3.07 & -3.02 \\
Romania & $-7.81^{a}$ & -7.78 & -6.77 & -5.11 \\
US & -7.46 & $-5.16^{a}$ & -4.45 & -3.58 \\
\hline \hline Levels & & & & \\
euro area & 0.27 & $-1.78^{a}$ & -1.62 & -2.05 \\
Bulgaria & $-1.81^{a}$ & -1.79 & -1.69 & -1.79 \\
Czech Rep. & -1.35 & $-1.59^{a}$ & -1.53 & -1.61 \\
Estonia & -0.64 & $-0.91^{a}$ & -0.83 & -1.06 \\
Hungary & -2.41 & $-2.53^{a}$ & -2.24 & -2.32 \\
Latvia & -1.52 & -2.11 & $-0.81^{a}$ & -0.61 \\
Lithuania & -4.56 & -2.29 & $-1.47^{a}$ & -1.46 \\
Poland & -2.08 & -2.18 & -2.48 & $-2.27^{a}$ \\
Romania & -3.89 & $-4.60^{a}$ & -2.32 & -1.48 \\
US & -0.73 & $-1.15^{a}$ & -1.42 & -1.52 \\
\hline
\end{tabular}

ADF test statistics for the levels are computed with an intercept. The $5 \%$ critical values are -1.94 for the first differences and -2.89 for the levels. Tests are conducted for different lag lengths $p$ with a maximum order of three, where the a in superscript denotes the order of augmentation chosen in the Dickey-Fuller regressions according to the AIC. 
Does the euro dominate Central and Eastern European money markets? Page 22

Table B.2: Cointegration rank statistics

\begin{tabular}{lccccc}
\hline & & & trace & \multicolumn{2}{c}{ critical values } \\
Country & $H_{0}$ & $H_{A}$ & statistic & $\mathbf{9 5 \%}$ & $\mathbf{9 0 \%}$ \\
\hline Bulgaria & $\mathrm{r}=0$ & $\mathrm{r}=1$ & 11.14 & 12.53 & 10.69 \\
Czech Rep. & $\mathrm{r}=0$ & $\mathrm{r}=1$ & 20.93 & 12.53 & 10.69 \\
Estonia & $\mathrm{r}=0$ & $\mathrm{r}=1$ & 14.86 & 12.75 & 10.79 \\
Hungary & $\mathrm{r}=0$ & $\mathrm{r}=1$ & 5.19 & 12.75 & 10.79 \\
Latvia & $\mathrm{r}=0$ & $\mathrm{r}=1$ & 16.83 & 12.75 & 10.79 \\
Lithuania & $\mathrm{r}=0$ & $\mathrm{r}=1$ & 27.20 & 12.75 & 10.79 \\
Poland & $\mathrm{r}=0$ & $\mathrm{r}=1$ & 19.56 & 12.53 & 10.69 \\
Romania & $\mathrm{r}=0$ & $\mathrm{r}=1$ & 27.07 & 12.75 & 10.79 \\
euro area & $\mathrm{r}=0$ & $\mathrm{r}=1$ & 16.93 & 12.80 & 10.82 \\
\hline
\end{tabular}

Critical values are simulated using 10,000 replications.

Table B.3: Weak exogeneity test results

\begin{tabular}{lrr}
\hline Country & t-statistic & p-value \\
\hline Bulgaria & 0.44 & 0.66 \\
Czech Rep. & 0.66 & 0.51 \\
Estonia & 0.01 & 0.99 \\
Hungary & - & - \\
Latvia & 0.04 & 0.96 \\
Lithuania & -0.03 & 0.97 \\
Poland & 0.50 & 0.62 \\
Romania & 1.54 & 0.13 \\
euro area & -0.81 & 0.42 \\
\hline
\end{tabular}

Hungary not included in the testing procedure due to lack of evidence for cointegration. 


\section{References}

Angeloni, I., Flad, M. and Mongelli, F. P. (2005). Economic and monetary integration of the new member states - helping to chart the route, ECB Occasional Paper Series No. 36.

Barro, R. J. and Gordon, D. B. (1983). Rules, discretion and reputation in a model of monetary policy, Journal of Monetary Economics 12: 101-121.

Bernanke, B. S. and Blinder, A. S. (1992). The Federal Funds rate and the channels of monetary transmission, American Economic Review 82: 901-921.

Coricelli, F., Égert, B. and MacDonald, R. (2006). Monetary transmission in Central and Eastern Europe: Gliding on a wind of change, Focus on European Economic Integration 1/06, Oesterreichische Nationalbank.

de Grauwe, P. (1989). Is the European Monetary System a DM-Zone?, CEPR Discussion Paper No. 297.

de Grauwe, P. and Mélitz, J. (eds) (2005). Prospects for monetary unions after the euro, MIT Press.

Dees, S., di Mauro, F., Pesaran, M. H. and Smith, L. V. (2007). Exploring the international linkages of the euro area: a global VAR analysis, Journal of Applied Econometrics 22: 1-38.

Dickinson, D. G. and Mullineux, A. W. (2001). Financial and Monetary Integration in the New Europe: convergence between the EU and Central and Eastern Europe, Edward Elgar.

Dvorsky, S., Scheiber, T. and Stix, H. (2008). The OeNB euro survey in Central, Eastern and Southeastern Europe - the 2008 spring wave update, Focus on European economic integration $2 / 08$.

Feridun, M. (2006). An investigation of the German Dominance Hypothesis in the context of the eastern enlargement of the EU, Prague Economic Papers 15: 172182.

Fratianni, M. and von Hagen, J. (1990). German Dominance in the EMS: the empirical evidence, Open Economies Review 1: 67-87.

Fratianni, M. and von Hagen, J. (1992). The Euopean Monetary System and European Monetary Union, Westview Press.

Giavazzi, F. and Giovanni, A. (1987). Models of the EMS: Is Europe a greater Deutschmark area?, in R. C. Bryant and R. Portes (eds), Global Macroeconomics, New York: St. Martin's Press, pp. 237-265.

Giavazzi, F. and Pagano, M. (1988). The advantage of tying one's hands - EMS discipline and central bank credibility, European Economic Review 32: 1055-1082. 
Granger, C. W. J. and Lin, J.-L. (1995). Causality in the long run, Econometric Theory 11: 530-536.

Hassapis, C., Pittis, N. and Prodromidis, K. (1999). Unit roots and Granger causality in the EMS interest rates: the German Dominance Hypothesis revisited, Journal of International Money and Finance 18: 47-73.

Hoover, K., Johansen, S. and Juselius, K. (2008). Allowing the data to speak freely: the macroeconometrics of Cointegrated Vector Autoregression, American Economic Review 98: 251-255.

Johansen, S. (1995). Likelihood-based Inference in Cointegrated Vector Autoregressive Models, Oxford University Press.

Kadow, A. (2007). Testing for Euro Dominance in Central and Eastern Europe, Master's thesis, Maastricht University.

Karfakis, C. J. and Moschos, D. M. (1990). Interest rate linkages within the European Monetary System: a time series analysis, Journal of Money, Credit and Banking 22: 388-394.

Katsimbris, G. M. and Miller, S. M. (1993). Interest rate linkages within the European Monetary System: further analysis, Journal of Money, Credit and Banking 25: $771-779$.

Kirchgässner, G. and Wolters, J. (1993). Does the DM dominate the euro market? An empirical investigation, Review of Economics and Statistics 75: 773-778.

Lewis, J. (2009). Hitting and hoping? Meeting the exchange rate and inflation criteria during a period of nominal convergence, European Journal of Political Economy 25: 508-524.

MacDonald, R. and Taylor, M. P. (1991). Exchange rates, policy convergence, and the European Monetary System, Review of Economics and Statistics 73: 553-558.

Pesaran, M. H., Schuerman, T. and Weiner, S. M. (2004). Modelling regional interdependencies using a global error-correcting macroeconometric model, (with discussion), Journal of Business and Economic Studies 22(2): 129-162 and 175181.

Pesaran, M. H., Shin, Y. and Smith, R. J. (2000). Structural analysis of vector error correction models with exogenous I(1) variables, Journal of Econometrics 97: 293-343.

Schadler, S., Drummond, P., Kuijs, L., Murgasova, Z. and van Elkan, R. (2005). Adopting the euro in Central Europe - challenges of the next step in European integration, IMF Occasional Paper No. 234.

Seitz, F. (1995). The circulation of Deutsche Mark abroad, Discussion Paper 1/95, Economic Research Group. 
Uctum, M. (1999). European integration and asymmetry in the EMS, Journal of International Money and Finance 18: 769-798.

von Hagen, J. and Fratianni, M. (1990). German dominance in the EMS: evidence from interest rates, Journal of International Money and Finance 9: 358-375. 